\title{
Developing the Cultural Heritage of Nyah-Kur Inhabitants as a Cultural Village Tourism and Sustainable Learning Center in Chaiyaphum, Thailand
}

\author{
Angsumalin Jamnongchob, Kingkanok Saowapawong, Jutatip Junead, and Unchun Tuntates
}

\begin{abstract}
Nyah Kul is a group of tribe, which means "people of the forest". The Thais call them Chaobon, meaning "people of the hills". The Nyah Kul consider this latter term derogatory. Due to integration into Thai society, the number of speakers of Nyah Kul language is rapidly decreasing and some predict the language will become extinct within the next century. The majority of Nyah Kul are in Chaiyaphum province where is located in the north eastern of Thailand or I-san region. Most live in mixed villages with Isan and Thai people. The village of Nyah Kul attracted many tourists to see their culture every day. It becomes the charming destination for the tourists to visit and find the story of place that link with traditional and way of life. The tourists can get special experiences through the tourism activities from local people. At the same time, locals can get more income and pride of their cultural. For this paper, the researcher used in-depth interviews and focus group as an instrument to understand the perspective of local people and tourism stakeholders. The results of this study confirm that Nyah Kul village has potential to be developed as a Cultural Village Tourism and Sustainable Learning Center. Moreover, tourism activities such as; cotton weaving, walking around the village, and attend their local festival should be promoted for upgrading tourism products. It also enables visitors to have cultural experience in the village.
\end{abstract}

Index Terms-Cultural village, hill tribe, learning center, tourism.

\section{INTRODUCTION}

The tourists' attractions in Chaiyaphum are interesting and very popular among tourists. According to statistics of the Reference [1] shows that the total numbers of tourists traveled to Chaiyaphum were $1,289,672$ persons, it can be divided into 1,281,735 of Thai tourists and 7,937 of foreign tourists. The province had approximately 2,108 rooms, occupancy rate was $50 \%$, the average length of stay was 2.02 days, the province data reported earnings of 1,265 million baht in tourism receipts, the average spending per capita was 651 baht per day, while majority of tourists visiting province were Thais, but there was a high potential for international tourists to significantly grow so the province needs the support from government to create the differences in Chaiyaphum's attractions such as Siam Tulip or Kra-jiao flower field, Pa Hin Ngam National Park, Mo Hin Khao plateau, Phu Khiao Wildlife Reserve, Sai Thong National Park, Chulaporn Dam and including the hill tribe village of

Manuscript received February 11, 2016; revised March 30, 2016.

A. Jamnongchob, K. Saowapawong, J. Junead, and U. Tuntates are with the Faculty of Environmental Culture and Ecotourism, Srinakharinwirot University, Thailand (e-mail: angsumalin@g.swu.ac.th, kingkanok@g.swu.ac.th, jutatipj@g.swu.ac.th, unchun@g.swu.ac.th).
Nyah-kur Inhabitants who are an ethnic group native to Thailand in Southeast Asia. Closely related to the Mon people, the Nyah-kur are the descendants of the Mon of Dvaravati who having remained isolated in the mountains between Central and Northeastern Thailand, they have had no close contacts with the outside world, which is why they have not been assimilated by the Khmer or Thai up to now, it allowed the Nyah-kur to maintain their own ethnic identity which developed independently from the Mon during the last thousand years yet in some respects shows remarkable similarity to modern Mon culture [2].

Today, the Nyah-kur live in small villages distributed in a north-south strip that crosses Phetchabun, Nakhon Ratchasima and Chaiyaphum provinces, the majority living in Chaiyaphum. The Thai refer to them as upper people or sky people. Their self-designation is Nyah-kur, which in the Nyah-kur language means mountain folk and in modern Mon translates to hill plantation people. Nyah-kur villages today are a mix of ethnic Nyah-kur and Thai-Lao families. The unique physical appearances of Nyah-kur are medium-sized body, big eyes, dark skin, and the women are beautiful. In the past females of the Nyah-kur ethnic tribe wore Sarong and Cylinder arm blouses, which called "Koh". They usually wore silver necklet, big earrings made of wood decorated with glazes, called "Kra-jorn". Male members of the tribe wore Sarong as well and would sometimes where a shirt. Nyah-kur Ethnic tribes in the past usually made their own clothing from cotton, which is a trade that they learned from the Thai-Lao tribe. Currently, modern clothing has replaced most traditional dresses and garments. Modern commerce and trends have led younger generations of Nyah-kur ethnic tribes to purchase clothing instead of making their own [3].

There are social event that unites the community and provide entertainment by incorporating songs filled with lyrics of love, caring reflecting the livelihood and unity of the community. The celebrations are carried out by songs and poetic lyrics from the male and female sides. The language used in the past was traditional Nyah-kur or what they refer to as Jungle language, but currently there are many words that are influenced from Thai-Lao and modern words. The Nyah-kur language is Austroasiatic language family of the Monic branch. Nyah-kur ethnic tribes used their native language, which is referred to as Pasa Dong or Jungle Dialect. Nyah-kur elders have passed on the Nyah-kur native language by speech without writing [4]. Most of the Nyah-kur villages today speak Thai and Lao, Nyah-kur language were eventually lost. Only the elders speak the Nyah-kur language and several villages do not have anyone left who can speak the language at all and have had to invite 
elders from other villages to teach on an hourly and weekly basis to preserve the dialect.

In order to prevent assimilate and loss of culture. It is crucial to have to understand the root causes, cultural heritage and local wisdom of the community which are unique and valuable. However, creating a better understanding of the past become the way to creating pride of their own cultural heritage. Affect the conservation and preservation of community identity as well. Thus, this study, the researchers try to develop Nyah-kur village to be the cultural village tourism and sustainable learning center by gathering information on the history, culture and traditions of the community. Moreover, it can be the way to encourage good awareness of conservation of cultural heritage and identity. Strengthen the ethnic communities. It also links the relationship of historical dimensions. Preserve the cultural heritage and traditional knowledge of communities and also bring income from tourism to the community with the equitable distribution.

\section{MATERIALS AND Methods}

For the completion of this research, a set of qualitative methods, principles and different approaches, tools and techniques were implemented. For research methods, the researchers have used group discussion methods which involved with community participation process to develop guidelines for Nyah-kur village to be the cultural village tourism and sustainable learning center. Retrospective data collection was mainly based on documentary sources, including previous studies, local databases (from local associations and institutions) and archives (of public speeches and industry reports), press archives of local and national newspapers, and databases. Real-time data collection was mainly based on in-depth interviews (directed towards local people and experts), participant observations of several events and gatherings hosted by the community and secondary sources (provincial web-site and archive, official press release, public reports). The interview was conducted in the period from August to October 2015. The target segment was consisted of the Nyah-kur villagers, head of community as well as the representatives of public sectors such as Tourism Authority of Thailand, Tourism and Sport office of the province, and the Cultural office. Moreover, the researchers checked for triangulation of different data sources in order to obtain more robust evidence. Descriptive Analysis was applied to comprehend the final data. The major results from this study are theoretical insights on how can tourism be synergic with cultural heritage in setting up a competitive advantage of Nyah-kur village as a cultural village tourism and sustainable learning center.

\section{RESULTS AND DISCUSSION}

The results obtained from this study are divided into two parts: the first part is the primary data that comes from previous research, the information from government and related organizations. The secondary data comes from an interview and focus group of stakeholders. The findings of both part is consistent. It can be lead to conclusions and become a guideline to development as a tourism village and sustainable learning center of Nyah-kur. It also includes the creation of income to the community from with fair distribution to the community as well.

The primary data found that the word Nyah-Kur also known as Nia-kuol is a family of Austroasiatic language family which is the same family with Mon, 1 of 14 languages that nearly lose such as Nyah-Kur, Sow, Chong, Kra-Chong, and Some-Re. By the way, the word "Nyah" means human, and "Kur" means mountain. So, the word Nyah-Kur means the people of mountain because they living in mountain and forests [5].

In the past, Nyah-Kur people lived on the high hill, and forest in Dong Rak Mountain. Their ways of life were concerned with animals hunting, and always change their place of living. By the year 1957 onwards, the Nyah-Kur people began migrating into a permanent base in the plains.

According to the study of [6] found that in 1979, there are Nyah-kur residential area located in Pak Thong Chai district, Nakhon Ratchasima province around 69 household which are divided into 113 males, and 133 female. Moreover, it can be found 200 people lived in Huai-Yae, and 100 people in Tha Pong, Nong Bua Ra We district, Chaiyaphum province. And there are 11 villages in Thep Sa Thit district comprise of Ban Rai sub-district 855 people, Na Yang Krak sub-district 930 people. They are also live in Ban-kwao district 377 people. Moreover, there are some families live in Petchaboon and Nakhon Ratchasima province.

The results of study from interview and focus group among stakeholders found that the Nyah-kur people did not give the importance of cultural and traditional preservation. One of reasons is the mix of culture between Northeast people of Thailand. Including the way to living in Thai society that have to use Thai language to communicate with other communities outside, and receive an education in the school that use Thai language as well. These are reasons why Nyah-kur people are not transmitted their language to children anymore.

In addition, Nyah-Kur language is regarded as a language without character, only spoken language which is quite difficult to pronounce. So, language, culture, traditions, and way of life of Nyah-Kur are going to lose gradually. On the other hand, outsiders' community such as researchers and linguists give big efforts to promote conservation and encourage the Nyah-Kur preserves their own culture and traditional ways of life such as dressing, eating and way of living.

According to the research founding, there are 8 tourist attractions in Nyah-Kur village in Na Yang Krak sub-district, Thep Sa Thit district, Chaiyaphum province, for example handicraft center, mats weaving demonstration, local games showing area, botanical garden, Nyah Kur language center, fortune teller, hunting, local food and desserts. Furthermore, in order to develop the potential of tourism attractions in Nyah-Kur village to be a learning center and source of income for the community comprises of 7 areas as following 1) a variety of cultural resources 2) the outstanding resource (place/objects/people) 3) cultural activities 4) attractiveness of existing resources 5) cultural and environmental maintaining 6) accessibility and 7) the availability of facilities such as tourist information center, signage etc. 
The communities were evaluated the potential of cultural attractions together with the researchers. There are 7 evaluation criteria including 1) having cultural resource for learning 2) cultural resource can be generate income to the community 3 ) convenient access to the village 4) having local guide and expertise in attraction 5) outstanding and interesting cultural resource 6) having public organization, community, or education sector to help and develop 7) people in the community are willing to make an assessment on the basis of the above. It was found that the cultural attractions in the Nyah-Kur village is the highlight of the program which can be attracting the most tourists and generate the most income for the local people; the second attraction is handicraft center, followed by local games showing area, mat weaving, local food and desserts cooking demonstration, Nyah-Kur language center, botanical garden, fortune teller, and hunting respectively.

Apart from above researches findings, researchers can be conclude and recommend the development guidelines of Nyah-Kur village for a cultural and learning center as following;

Strengthening the people in the community.

The process of creating sustainable tourism community depending strong sense of community identity and pride, love, cherish the culture and traditional way of life. It allows people in the community can adapt themselves to not be merged with other cultures.

Local community's knowledge management

By collecting and storing remaining wisdom and published all culture, wisdom, and knowledge to close people, child, the community, and academics person who interested in this area to take written notes and preparation of documents for dissemination to the public.

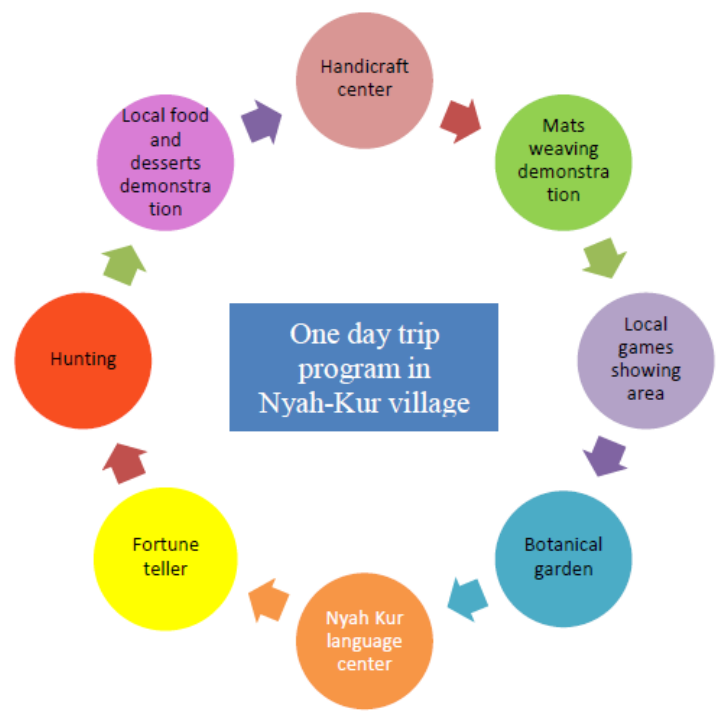

Fig. 1. One day trip program in Nyah-Kur village.

Encouraging people in the community aware of the value of cultural, and way of life by bringing knowledge to use and applied in everyday life. Enhance collaboration between the community, such as schools and government offices culture. Local tourist offices in order to share and learn together, including promotes activities and culture of the community to be widely recognized as permanent and semi-permanent exhibitions. Establishing cultural centers to provide information to tourists, and setting up cooperative to encourage community revenues from product sales in the community.

However, the activities of cultural tourism and local life of Nyah-Kur are unique and interesting. Visitors can choose from a variety of activities based on their interests to study the wisdom traditions, culture and way of life which are demonstrating the long-standing civilization that transmitted from generation to generation until the present. Visitors will receive a special experience, fun and incorporating with knowledge from activities such as learning how to weave traditional mat, cooking local food and dessert. There are also providing the standardized geographic pattern of tourist activities which concerned with crops, animal hunting, experiments play and traditional play of Nyah-Kur village. The one day trip program defines the eight main activities in the village as shown in Fig. 1.

\section{CONCLUSION}

In conclusion, the researchers can confirm that Nyah-Kur village has potential to be developed as a cultural tourism village and learning center. Moreover, tourism activities such as; walking around the village, mat weaving, cooking class, and join the festival of the community should be promoted for upgrading tourism products. It also enables visitors to experience cultural experience in Chaiyaphum province and generate more income to the community as well.

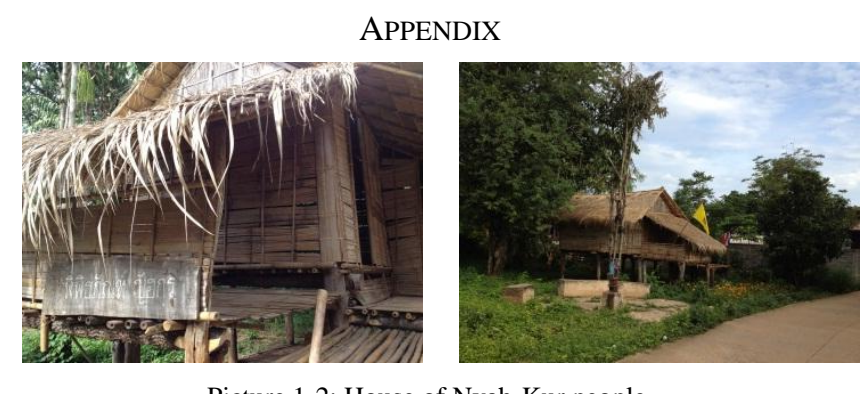

Picture 1-2: House of Nyah-Kur people.

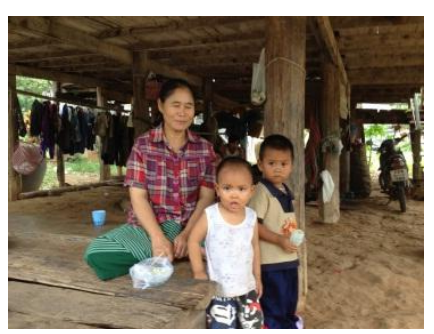

Picture 3: Nyah-Kur people.

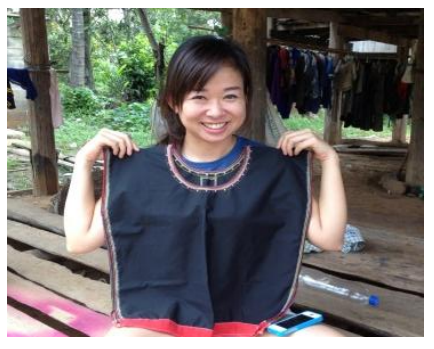

Picture 5: Cylinder arm blouses

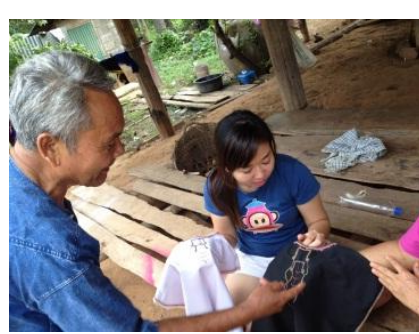

Picture 4: Local clothes

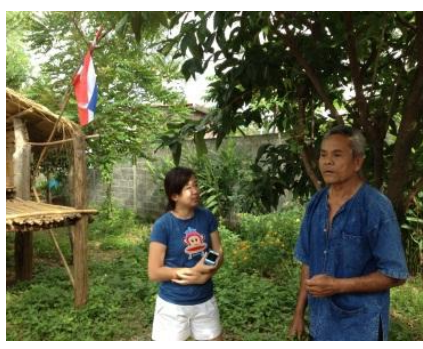

Picture 6: Talk with Nyah-Kur

\section{ACKNOWLEDGMENT}

This research paper was supported by the funding of 
Faculty of Environmental Culture and Ecotourism, Srinakharinwirot University, Bangkok, Thailand. It is also made possible through the help and support from everyone, including: my boss, colleague, all stakeholders and the community in Chaiyaphum province. The product of this research paper would not be possible without all of them.

\section{REFERENCES}

[1] Chaiyaphum provincial office of tourism and sport. (May 2013). Tourist Arrivals in Chaiyaphum province in 2012. [Online]. Available: http://www.chaiyaphum.nso.go.th/

[2] N. P. Hla, The Major Role of the Mons in Southeast Asia, Bangkok, Thailand, 1991, pp. 13-19.

[3] Supisara et al., "Guidelines and methods for conservation, revitalization and development of the traditions and customs of nyah Kur ethnic group for tourism in the province of chaiyapum in northeast Thailand," Social Sciences Journal, vol. 4, issue 2, pp. 174-179, 2009.

[4] Diffloth, The Dvaravati Old Mon Language and Nyah Kur, Bangkok, Thailand: Chulalongkorn University, 1984.

[5] Theraphan, "Rhythm in Nyah Kur (Chao Bon)," Journal of Letters, vol. 21, no. 1, pp. 118-144, 1984

[6] P. Sukgasem, "Phonological Interference between Kuay and Northeastern Thai in Surin," M.A. dissertation, Mahidol University, 1988.

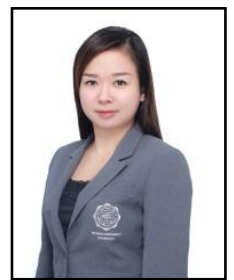

Angsumalin Jamnongchob was born in Nakhonsawan, Thailand, in 1984. She received the B.A. degree in tourism management from Naresuan University International College, Phitsanulok, Thailand, in 2007, and the M.A. degrees in international tourism and hospitality managemen program which is double degree from Naresuan University, Thailand and Southern Cross University, Australia, in 2009. During she studied her master degree, she was recruited as a staff at Tourism Authority of Thailand, one of the public tourism organization in Thailand for two years. Then, she had a great opportunity to work as a full-time instructor at Naresuan University International College. In 2010, she started her Ph.D. degree in sport, recreation, and tourism at Srinakharinwirot University, Bangkok, Thailand. In, 2012, she joined the Faculty of Environmental Culture and Ecotourism, Srinakharinwirot University, as a lecturer. Her current research interests include tourism marketing, destination management, adventure tourism, sustainability and tourism development in developing countries, with a particular focus on Thailand.

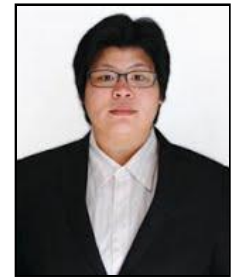

Kingkanok Saowapawong was born in Bangkok, Thailand, in 1984. She received the B.A. degree in tourism management from Dusit Thani College, Thailand, in 2007, and the M.A. and Ph.D. degrees in recreation and tourism management from Chulalongkorn University, Thailand in 2009 and 2014, respectively. During she studied her master degree, she worked as a teacher assistant at the Faculty of Sport Science, Chulalongkorn University, Thailand. In, 2014, she joined the Faculty of Environmental Culture and Ecotourism, Srinakharinwirot University, as a lecturer. Her current research interests include sport tourism, recreation activities, adventure tourism.

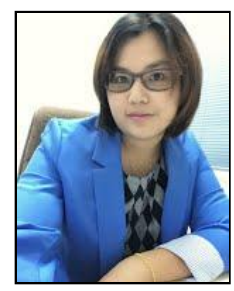

Jutatip Junead was born in Yala, Thailand, in 1985. She received the B.A. degree in Chinese language from Huachiew Chalermprakiet University, Bangkok, Thailand, in 2007, and the M.A. degrees in tourism and hospitality management from Naresuan University, Thailand. In 2011, she started her Ph.D. degree in tourism at University of Phayao, Bangkok, Thailand. In 2015, she joined the Faculty of Environmental Culture and Ecotourism, Srinakharinwirot University, as a lecturer. Her current research interests include tourism planning, community based tourism, creative tourism, sustainability and tourism development.

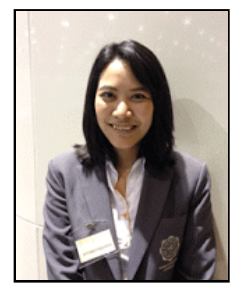

Unchun Tuntates was born in Bangkok, Thailand, in 1985. She received the B.S. degree in forestry from Kasetsart University, Bangkok, Thailand, in 2008 , and the M.S. degrees in parks, recreation, and tourism degree from Kasetsart University, Thailand in 2011 In, 2012, she joined the Faculty of Environmental Culture and Ecotourism, Srinakharinwirot University, as a researcher. In 2014, she started her Ph.D. degree in architectural heritage management and tourism (international program) at Silapakorn University, Bangkok, Thailand. Her current research interests include ecotourism, sustainability and tourism development, and community based tourism. 